\title{
Ionization Mechanism of Negative Ion-Direct Analysis in Real Time: A Comparative Study with Negative Ion-Atmospheric Pressure Photoionization
}

\author{
Liguo Song, Andrew B. Dykstra, Huifang Yao, and John E. Bartmess \\ Mass Spectrometry Center, Department of Chemistry, University of Tennessee, Knoxville, Tennessee, USA
}

\begin{abstract}
The ionization mechanism of negative ion-direct analysis in real time (NI-DART) has been investigated using over 42 compounds, including fullerenes, perfluorocarbons (PFC), organic explosives, phenols, pentafluorobenzyl (PFB) derivatized phenols, anilines, and carboxylic acids, which were previously studied by negative ion-atmospheric pressure photoionization (NI-APPI). NI-DART generated ionization products similar to NI-APPI, which led to four ionization mechanisms, including electron capture (EC), dissociative EC, proton transfer, and anion attachment. These four ionization mechanisms make both NI-DART and NI-APPI capable of ionizing a wider range of compounds than negative ion-atmospheric pressure chemical ionization (APCI) or negative ion-electrospray ionization (ESI). As the operation of NI-DART is much easier than that of NI-APPI and the gas-phase ion chemistry of NI-DART is more easily manipulated than that of NI-APPI, NI-DART can be therefore used to study in detail the ionization mechanism of LC/NI-APPI-MS, which would be a powerful methodology for the quantification of low-polarity compounds. Herein, one such application has been further demonstrated in the detection and identification of background ions from LC solvents and APPI dopants, including water, acetonitrile, chloroform, methylene chloride, methanol, 2-propanol, hexanes, heptane, cyclohexane, acetone, tetrahydrofuran (THF), 1,4-dioxane, toluene, and anisole. Possible reaction pathways leading to the formation of these background ions were further inferred. One of the conclusions from these experiments is that THF and 1,4-dioxane are inappropriate to be used as solvents and/or dopants for LC/NI-APPI-MS due to their high reactivity with source basic ions, leading to many reactant ions in the background. (J Am Soc Mass Spectrom 2009, 20, 42-50) () 2009 Published by Elsevier Inc. on behalf of American Society for Mass Spectrometry
\end{abstract}

$\mathrm{R}$ ecently, several newly developed ionization methods, including direct analysis in real time (DART) [1], desorption electrospray ionization (DESI) [2], desorption atmospheric pressure chemical ionization (DAPCI) [3], and desorption atmospheric pressure photoionization (DAPPI) [4], have attracted more and more attention due to their abilities in ionization of samples at ambient or open air conditions and/or their ability in direct analysis of samples without prior treatment. In comparison with traditional atmospheric pressure ionization (API) methods, including electrospray ionization (ESI) [5, 6], atmospheric pressure chemical ionization (APCI) [7] and atmospheric pressure photoionization (APPI) [8, 9], these new ionization methods are especially successful in the analysis of compounds on a variety of surfaces, including concrete, human skin, currency, airline boarding passes, fruits, vegetables, cloth, drug tablets, and bio-

Address reprint requests to Dr. L. Song, Mass Spectrometry Center, Department of Chemistry, University of Tennessee, 617 Buehler Hall, Knoxville, TN 37996-1600, USA. E-mail: song@ion.chem.utk.edu logical tissues without sample preparation. Of these new ionization methods, DART is particularly interesting due to its distinct ionization mechanism, while the others have close relationships with their respective traditional API methods.

DART ionization begins with a stream of gas, usually helium, which is electrically discharged to produce ions, electrons, and metastable species. After heating and removal of charged particles, this stream of gas exits the DART source into the open air, and is able to ionize chemicals by instant contact, therefore permitting the analysis of gases, liquids, and solids. Although the DART ionization mechanisms are not yet fully understood, it has been proposed [1] that in the positive ion (PI) mode, metastable helium atoms induce Penning ionization of ambient water in the open air, generating protonated water clusters, mostly $\mathrm{H}_{5} \mathrm{O}_{2}^{+}$, which further ionize analytes through chemical reactions. In the negative ion (NI) mode; however, it has been proposed [1] that thermal electrons, which are generated from the collision between electrons and gas molecules in the open air, undergo electron capture by atmospheric
(C) 2009 Published by Elsevier Inc. on behalf of American Society for Mass Spectrometry. 1044-0305/09/\$32.00

doi:10.1016/j.jasms.2008.09.016
Published online September 23, 2008

Received June 24, 2008

Revised September 12, 2008

Accepted September 12, 2008 
oxygen to generate $\mathrm{O}_{2}^{-}$, which further ionizes analytes through chemical reactions. So far, DART has demonstrated success in the ionization of hundreds of chemicals, including chemical agents and their signatures, pharmaceuticals, metabolites, synthetic organics, organometallics, drugs of abuse, explosives, toxic industrial chemicals, etc. [1]. The application of DART for the analysis of flavor and fragrance raw materials from real samples [10], fatty acid methyl esters from bacterial whole cells [11], sample zones from high-performance thin-layer chromatography (HPTLC) [12], organic synthetic products from drug discovery [13], and selfassembled monolayers on gold surfaces [14] are especially intriguing.

Unlike the newly developed "ambient" ionization methods, traditional API methods facilitate online coupling with liquid chromatography (LC), therefore offering superior quantification. They have found wide applications in the quantification of pharmaceutically, biologically, and environmentally significant compounds of various origins. Of the three traditional API methods, APPI is the latest developed [8,9] and is anticipated to expand the polarity range of analytes amenable to LC/API-MS to include low-polarity compounds $[15,16]$. So far, LC/PI-APPI-MS has been demonstrated to be effective in the analysis of hydrophobic lipids [17, 18] and compounds containing conjugated aromatic rings $[8,19-24]$. On the other hand, our recent studies [25, 26] have demonstrated that NI-APPI is highly efficient in the ionization of low-polarity compounds possessing positive electron affinities (EAs), implying that LC/NI-APPI-MS may permit the analysis of nonvolatile, low polarity compounds with the sensitivity and selectivity that gas chromatography negative ion chemical ionization mass spectrometry (GC/NICIMS) delivers for volatile nonpolar compounds.

Similar to NI-DART, NI-APPI is also believed to be initiated by electrons, which are by-products of PIAPPI, where molecules absorb photons to generate molecular radical cations. However, unlike NI-DART, these electrons are stabilized through their collision with ultra-high-purity (UHP) nitrogen, which is usually used as nebulizer and/or heater gas in an enclosed APPI source chamber, rather than atmospheric gas in open air. Therefore, it is understandable that electron capture (EC) and dissociative EC ionization mechanisms were found highly efficient when NI-APPI was used to analyze low-polarity compounds possessing positive EAs [25, 26]. At the same time, however, experimental evidence also suggested constant existence of $\mathrm{O}_{2}^{-\cdot}$ [26-28], an EC product of oxygen that must come from the atmosphere, in an APPI source. Due to the coexistence of thermal electrons and $\mathrm{O}_{2}^{-}$, four ionization mechanisms, including EC, dissociative EC, proton transfer, and anion attachment, which were found to sometimes compete with each other, have been identified for NI-APPI. When coupled with LC using gradient elution, NI-APPI is expected to be further complicated by the involvement of LC solvents and buffer additives into the ionization process.

As both NI-DART and NI-APPI are believed to be initiated by thermal electrons, a comparative study may provide more insights to the ionization mechanism of both NI-DART and NI-APPI. Therefore, we selected over 42 compounds, which were formerly studied by NI-APPI, to be analyzed by NI-DART. Since DART is an ambient or open air ion source, the amount of thermal electrons in the NI-DART helium gas stream may be very low due to their fast reaction with ambient $\mathrm{O}_{2}$, causing insignificant EC and dissociative EC ionization. Surprisingly, similar ionization products were observed, implying similar ionization mechanisms between these two techniques. As the operation of NIDART is much easier than that of NI-APPI and the gas-phase ion chemistry of NI-DART is more easily manipulated than that of NI-APPI, NI-DART can therefore be used to study in detail the ionization mechanism of LC/NI-APPI-MS, which would be a powerful methodology for the quantification of low-polarity compounds. One such application has been further demonstrated in the detection and identification of background ions generated from common LC solvents and APPI dopants. Previous NI-APPI studies by others [27, 28] have not detected and/or identified many important background ions from common LC solvents and APPI dopants, partly because the mass spectrometers discriminated against low $m / z$ values. In addition, the resolution of those mass spectrometers was also low, making it difficult to identify the detected ions.

\section{Experimental}

Reagents

All solvents, including water, acetonitrile, chloroform, methylene chloride, methanol, 2-propanol, hexanes, heptane, cyclohexane, acetone, tetrahydrofuran (THF), 1,4dioxane, toluene, and anisole, were HPLC grade and purchased from Fisher Scientific (Suwanee, GA). Reserpine, PEG 200, PEG 600, 2,4,6-trimethylbenzoic acid, decanoic acid, 3-fuoroaniline, 3-trifluoromethylaniline, and 3-nitroaniline were purchased from Aldrich Chemical (St. Louis, MO). 2-Methylbenzoic acid was purchased from TCI (Wellesley Hills, MA). 4-Cyanoaniline was purchased from Fluka (St. Louis, MO). $\mathrm{C}_{60}$ and $\mathrm{C}_{70}$ fullerenes were purchased from Strem Chemicals (Newburyport, MA). $\mathrm{C}_{60} \mathrm{~F}_{48}$ fullerene was synthesized according to a published procedure [29]. Perfluoropentane, perfluoromethylcyclohexane $(\mathrm{PMCH})$, and perfluorokerosene (PFK), a mixture of perfluorinated hydrocarbons, were purchased from PCR Research Chemicals (Gainesville, FL). 1,3-Dinitrobenzene (1,3DNB), 2-amino-4,6-dinitrotoluene (2-amino-4,6-DNT), 2,4-dinitrotoluene (2,4-DNT), 2,4,6-trinitrotoluene (TNT), 1,3,5-trinitrobenzene (1,3,5-TNB), RDX, and HMX were purchased from AccuStandard (New Haven, CT). Phenol, 2,4-dimethylphenol, 2-chlorophenol, 2-nitrophenol, 
4-nitrophenol, 4-chloro-3-methylphenol, 2,4-dichlorophenol, 2,4-dinitrophenol, 2,4,6-trichlorophenol, 2-methyl-4,6dinitrophenol, pentachlorophenol, and their corresponding pentafluorobenzyl (PFB) derivatives were also purchased from AccuStandard.

\section{Apparatus}

All experiments were performed using a JEOL JMST100LC (AccuTOF) orthogonal time-of-flight (TOF) mass spectrometer (Peabody, MA) with an IonSense (Danvers, MA) DART source. The DART source used helium gas at a flow rate of $4 \mathrm{~L} / \mathrm{min}$. The gas heater, needle voltage, electrode 1 voltage, and electrode 2 voltage of the DART source were set to $300{ }^{\circ} \mathrm{C}, 3000$, -150 and $-250 \mathrm{~V}$, respectively. The general controlling parameters for the AccuTOF, which was operated at a resolution power of over 6000 (FWHM, full width at half maximum) for reserpine, were orifice 1 temperature, $80^{\circ} \mathrm{C}$; orifice 1 voltage, $20 \mathrm{~V}$; orifice 2 voltage, $3 \mathrm{~V}$; ring lens voltage, $3 \mathrm{~V}$. The distance between the outlet of the DART gas and the inlet of the orifice 1 of the AccuTOF was $\sim 1 \mathrm{~cm}$. Sample introduction was accomplished by slowly moving the closed end of a melting point capillary, which was dipped into a solution of the analytes so that $\sim 2 \mu \mathrm{L}$ of sample was carried across the helium gas stream between the DART source and the orifice 1 of the AccuTOF. Ionization was instant once helium evaporated the sample solvent. The system was calibrated with a mixture solution of $2.5 \mu \mathrm{L} / \mathrm{mL}$ PEG 200 and $50 \mu \mathrm{L} / \mathrm{mL}$ PEG 600 in methanol using $\left[\mathrm{M}+\mathrm{O}_{2}-\mathrm{H}\right]^{-}$and $\left[\left(\mathrm{C}_{2} \mathrm{H}_{4} \mathrm{O}\right)_{n}+\mathrm{O}_{2}-\mathrm{H}\right]^{-}$ion series. The spectra recording interval was $0.5 \mathrm{~s}$. Sample introduction, $\sim 2 \mu \mathrm{L}$ each time, was repeated six times to generate six chromatographic peaks in each TIC chromatogram. Each spectrum shown in the figures represents the corresponding spectrum at the maximum of a TIC chromatogram. This is different from our previous studies with NI-APPI, where infusion was used. To better compare the limit of detection (LOD) estimated in these two studies, the signal to noise $(\mathrm{S} / \mathrm{N})$ ratio of a NI-DART spectrum should be amplified by a factor of FWHM from its corresponding chromatographic peak (usually two to five times) to represent the peak area, which was not employed in the Results and Discussion section. It is noted, however, the NI-DART ionization was optimized to minimize in-source fragmentation rather than to maximize its sensitivity. The comparison was only a rough estimation to better understand the ionization mechanism.

\section{Results and Discussion}

\section{Analysis of Fullerenes}

Fullerenes are compounds with a spherical core of highly conjugated carbon rings, which grants them high positive EAs, e.g., 2.7, 2.8, and $4.2 \mathrm{eV}$ being reported for $\mathrm{C}_{60}, \mathrm{C}_{70}$, and $\mathrm{C}_{60} \mathrm{~F}_{48}$, respectively [30-32]. Our previous study [25] demonstrated that NI-APPI was highly efficient in the ionization of $\mathrm{C}_{60}, \mathrm{C}_{70}$, and $\mathrm{C}_{60} \mathrm{~F}_{48}$, and a limit of detection (LOD) of $0.15 \mathrm{pg}$ was achieved for $\mathrm{C}_{60}$. Because highly abundant $\mathrm{M}^{-\cdot}$ ions were observed, the ionization was attributed to an EC mechanism. In comparison with NI-APPI, NI-DART was inefficient in the ionization of $\mathrm{C}_{60}, \mathrm{C}_{70}$, and $\mathrm{C}_{60} \mathrm{~F}_{48}$, with $\mathrm{S} / \mathrm{N}$ ratio of $\sim 100$, 50, and 400 for respective $400 \mathrm{ng} \mathrm{C}_{60}, \mathrm{C}_{70}$, and $\mathrm{C}_{60} \mathrm{~F}_{48}$ in toluene, even though ionization products similar to those detected with NI-APPI were observed (spectra not shown). These results appeared to suggest that EC ionization was insignificant in NI-DART. However, additional experiments with more analytes suggested that NI-DART was generally less efficient than NI-APPI.

\section{Analysis of Aliphatic Perfluorocarbons (PFCs)}

In comparison with fullerenes, aliphatic PFCs are much more volatile. At the same time, they also possess positive EAs. Our previous study [25] demonstrated that NI-APPI was efficient in the ionization of aliphatic PFCs. Dominant $[\mathrm{M}-\mathrm{F}]^{-}$ions were observed, which was attributed to an EC mechanism for the formation of $\mathrm{M}^{-\cdot}$ ions, and thereafter instant in-source decomposition of the $\mathrm{M}^{-\cdot}$ ions for the formation of $[\mathrm{M}-\mathrm{F}]^{-}$ions. Here NI-DART was first used to ionize perfluoropentane and PMCH (data not shown). While dominant $\mathrm{M}^{-}$. ions were observed for both perfluoropentane and $\mathrm{PMCH}$, abundant $[\mathrm{M}-\mathrm{F}]^{-}$ions were also observed with over $2 / 3$ relative intensity to the $\mathrm{M}^{-\cdot}$ ions. The experiments appeared to support an EC mechanism for the formation of $\mathrm{M}^{-\cdot}$ ions. In addition, they might also support a dissociative EC mechanism for the formation of $[\mathrm{M}-\mathrm{F}]^{-}$ions. Although in-source decomposition of the $\mathrm{M}^{-\cdot}$ ions might also explain the existence of $[\mathrm{M}-\mathrm{F}]^{-}$ ions, it might be unlikely as the orifice 1 voltage was only $20 \mathrm{~V}$. Charge exchange between $\mathrm{O}_{2}^{-}$and the analytes might also occur to generate $\mathrm{M}^{-\cdot}$ ions, but it would be difficult to distinguish from EC ionization.

Figure 1 demonstrates a NI-DART spectrum of $\sim 100$ pL PFK in toluene. Compared with the previously reported NI-APPI spectrum of $\sim 667 \mathrm{fL}$ PFK in toluene [25], NI-DART was $\sim 100$ times less sensitive than NI-APPI. Furthermore, the NI-DART spectrum of PFK was more like a NICI spectrum of PFK where an even number of fluorines was easily found for the high $\mathrm{m} / \mathrm{z}$ ions, while the NI-APPI spectrum of PFK was more like an electron ionization (EI) spectrum of PFK where mostly an odd number of fluorines were found for any ions.

\section{Analysis of Nitrated Explosives}

Nitroaromatic explosives possess high positive EAs and some of them strong gas-phase acidities. Our previous study [26] demonstrated that NI-APPI was highly efficient in the ionization of nitroaromatic explosives, resulting in $\mathrm{M}^{-},[\mathrm{M}-\mathrm{H}]^{-}$, and $\left[\mathrm{M}-\mathrm{NO}^{-}\right.$ions, which 


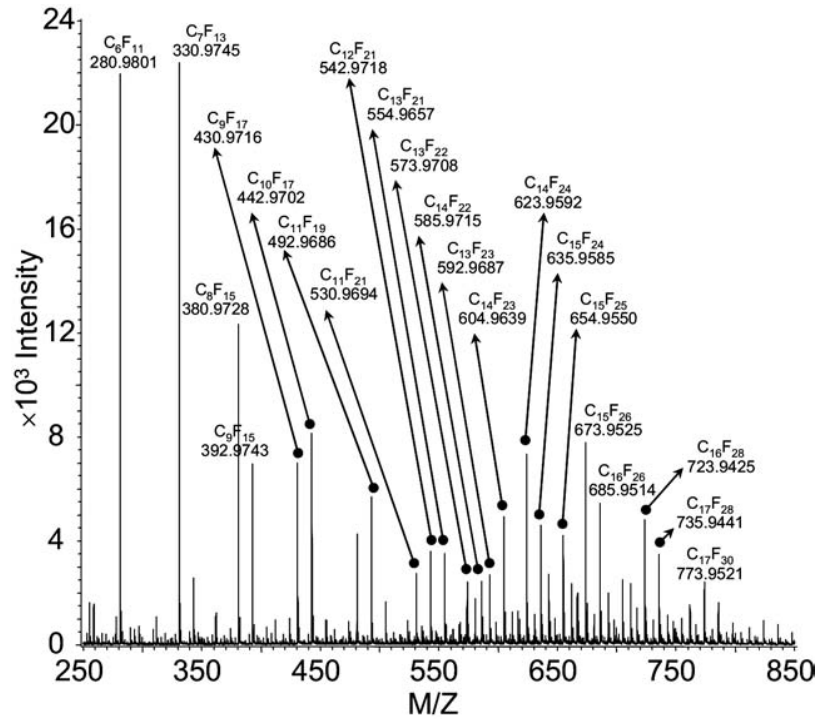

Figure 1. NI-DART spectrum of $\sim 100 \mathrm{pL}$ PFK in toluene at a concentration of $100 \mu \mathrm{L} / \mathrm{mL}$.

were attributed to three ionization mechanisms including EC, dissociative EC, and proton transfer. Figure 2 demonstrates a NI-DART spectrum of $\sim 4 \mathrm{ng}$ nitrobenzene, 1,3-DNB, 2,4-DNT, 2-amino-4,6-DNT, 1,3,5-TNB, and $2,4,6-\mathrm{TNT}$ in a solvent mixture of $50 / 50$ methanol and acetonitrile.

The ionization of 1,3-DNB and 1,3,5-TNB by both NI-DART and NI-APPI showed both $\mathrm{M}^{-\cdot}$ and [M $\mathrm{NO}]^{-}$ions, with less $[\mathrm{M}-\mathrm{NO}]^{-}$ions being generated by NI-DART. The experiments appeared to support an EC mechanism for the formation of $\mathrm{M}^{-\cdot}$ ions. In addition, they might also support a dissociative EC mechanism for the formation of $\left[\mathrm{M}-\mathrm{NO}^{-}\right.$ions. Although in-source fragmentation of the $\mathrm{M}^{-\cdot}$ ions might also explain the existence of $\left[\mathrm{M}-\mathrm{NO}^{-}\right.$ions, it might be unlikely as the orifice 1 voltage was only $20 \mathrm{~V}$ for NI-DART. Charge exchange between $\mathrm{O}_{2}^{-.}$and the analytes might also occur to generate $\mathrm{M}^{-\cdot}$ ions, but it would be difficult to distinguish from EC ionization.

The ionization of 2,4-DNT, 2-amino-4,6-DNT, and 2,4,6-TNT by NI-DART showed $\mathrm{M}^{-},[\mathrm{M}-\mathrm{H}]^{-}$, and $[\mathrm{M}-\mathrm{NO}]^{-}$ions, while much more dominant $[\mathrm{M}-\mathrm{H}]^{-}$ ions were generated by NI-APPI. Again, the experiments appeared to support an EC mechanism for the formation of $\mathrm{M}^{-\cdot}$ ions, and might also support a dissociative EC mechanism for the formation of $\left[\mathrm{M}-\mathrm{NO}^{-}\right.$ ions. The $[\mathrm{M}-\mathrm{H}]^{-}$ions may be mainly produced by proton transfer between the analytes and $\mathrm{O}_{2}^{-.}$due to their stronger gas-phase acidity than $\mathrm{HO}_{2}$.

NI-DART has shown very high sensitivity in the ionization of nitroaromatic explosives, at least three orders of magnitude higher than fullerenes. However, it was still $\sim 50$ times less sensitive than NI-APPI with a LOD of $\sim 90 \mathrm{fg}$ [26].

Although nitroamines, i.e., RDX and HMX, do not possess either positive EAs or appreciable gas-phase acidity, our previous study [26] demonstrated that
NI-APPI was highly efficient in the ionization of nitroamines through anion, e.g., $\mathrm{Cl}^{-}, \mathrm{Br}^{-}$, or $\mathrm{I}^{-}$, attachment. In this study, our experiments further demonstrated that, similar to NI-APPI, NI-DART was also very efficient in ionizing nitroamines through anion attachment (data not shown) when halogenated solvents were used.

\section{Analysis of Phenols and Their PFB Derivatives}

With NI-APPI, PFB derivatized phenols underwent a signature dissociative EC reaction and generated exclusively negative phenolate anions [25], which were the same as NICI and NI-APCI. To further study the ionization mechanism of NI-DART, phenol, 2,4-dimethylphenol, 2-chlorophenol, 2-nitrophenol, 4-nitrophenol, 4-chloro-3methylphenol, 2,4-dichlorophenol, 2,4-dinitrophenol, 2,4,6-trichlorophenol, 2-methyl-4,6-dinitrophenol, pentachlorophenol, and their corresponding pentafluorobenzyl (PFB) derivatives were studied, and the corresponding spectra of $4 \mathrm{ng}$ analytes in methanol are shown in Figure $3 \mathrm{a}$ and $\mathrm{b}$. The chlorinated anions can be easily distinguished from others using their distinct isotopic patterns.

Deprotonated ions were observed for all the phenols by NI-DART, which could be mainly attributed to a proton transfer ionization mechanism as they possess stronger gas-phase acidity than $\mathrm{HO}_{2}$. Similar to NIAPPI, only phenolate anions were observed by NIDART for PFB derivatized phenols, which could be easily attributed to a dissociative EC mechanism. The ionization of PFB derivatized phenols by NI-DART was also at least two times more efficient than the ionization of phenols, although 2-methyl-4,6-dinitrophenol was an exception. These results also agreed well with those by NI-APPI [25]. NI-DART has shown very high sensitiv-

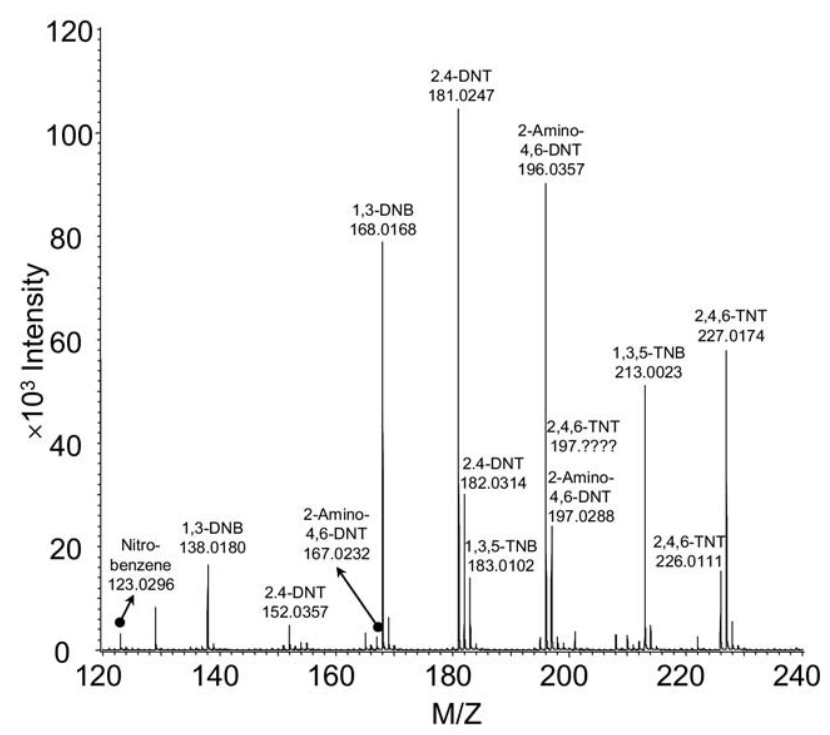

Figure 2. NI-DART spectrum of $\sim 4$ ng nitrobenzene, 1,3-DNB, 2,4-DNT, 2-amino-4,6-DNT, 1,3,5-TNB, and 2,4,6-TNT in a solvent mixture of 50/50 methanol and acetonitrile at a concentration of 2 $\mu \mathrm{g} / \mathrm{mL}$. 

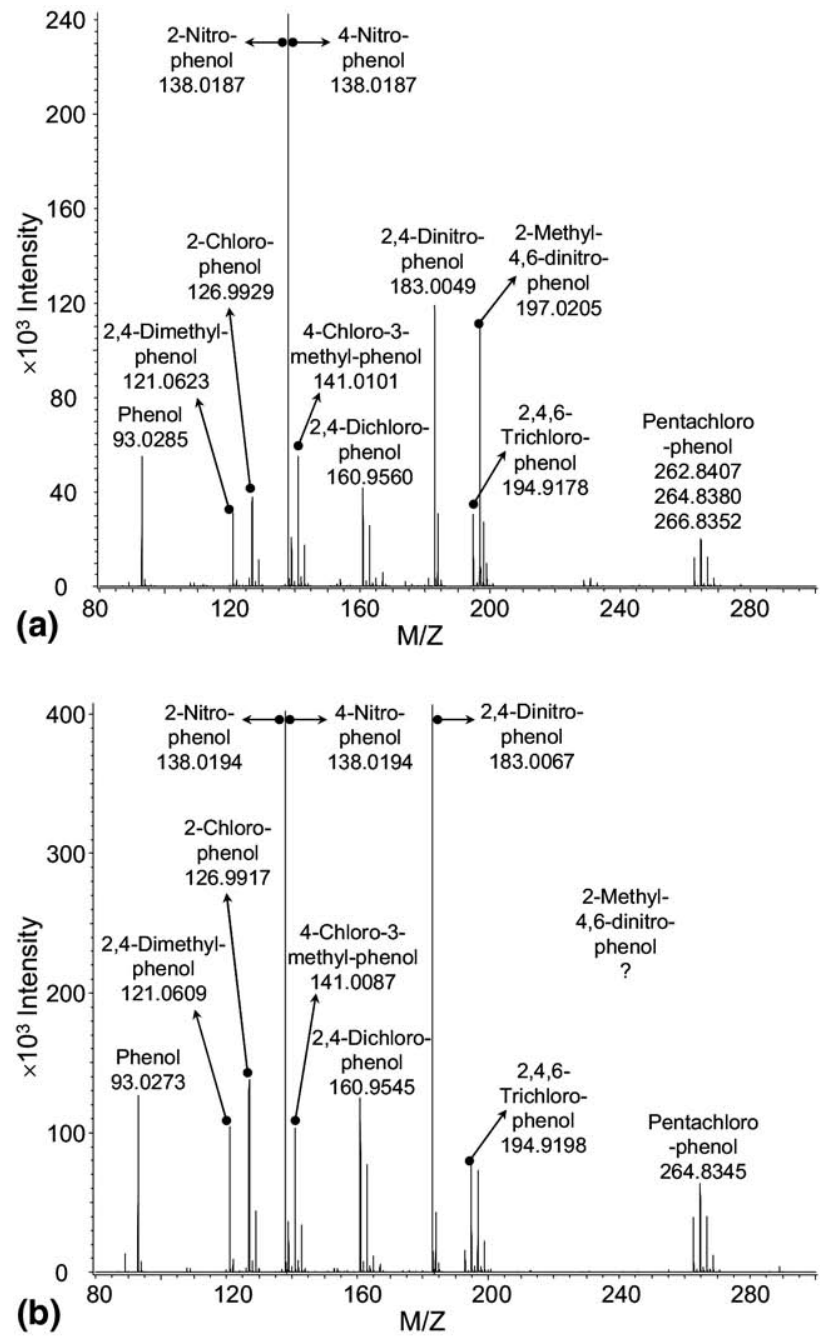

Figure 3. NI-DART spectra of $\sim 4 \mathrm{ng}$ phenol, 2,4-dimethylphenol, 2-chlorophenol, 2-nitrophenol, 4-nitrophenol, 4-chloro-3-methylphenol, 2,4-dichlorophenol, 2,4-dinitrophenol, 2,4,6-trichlorophenol, 2-methyl-4,6-dinitrophenol, pentachlorophenol (a), and their corresponding pentafluorobenzyl (PFB) derivatives (b) in methanol at a concentration of $2 \mu \mathrm{g} / \mathrm{mL}$.

ity in the ionization of PFB derivatized phenols, and it was only $\sim 5$ times less sensitive than NI-APPI with a LOD of $\sim 170 \mathrm{fg}$ for 2,4-dinitrophenol [25].

\section{Analysis of LC Solvents and APPI Dopants}

It has been well recognized that the ionization process in APPI is complicated, which is especially true for LC/ APPI-MS because many reactants, including nebulizing gas, auxiliary gas, surrounding air, dopant, solvent, buffer additives, and impurities, are involved. The reactant ions in an LC/NI-APPI-MS system can be categorized into three generations. The first generation is thermal electrons, which are by-products of PI-APPI where dopant molecules absorb photons to generate molecular radical cations. The second generation of reactant ions, e.g., $\mathrm{O}_{2}^{-}$, is produced by the reaction of thermal electrons with nebulizing gas, auxiliary gas, and surrounding air. The third generation of reactant ions is produced by the reaction of the second generation of reactant ions with APPI dopants, LC solvents, buffer additives, etc. Analytes are finally ionized through their reaction with the reactant ions in the LC/NI-APPI-MS system.

Background ions in an APPI system have been studied on a few occasions [26-28, 33, 34], mostly for PI-APPI. Kauppila et al. [27, 28] studied background ions from common LC solvents and APPI dopants for NI-APPI. However, many important background ions were not detected because the mass spectrometers discriminated against low $\mathrm{m} / \mathrm{z}$ values. In addition, the resolution of those mass spectrometers was also low, making it difficult to identify the detected ions. Although we investigated the background ions from toluene using a high-resolution mass spectrometer [26], the mass spectrometer also discriminated against low $\mathrm{m} / \mathrm{z}$ values.

The operation of NI-DART is much easier than that of NI-APPI. Furthermore, our experiments using NIDART for the ionization of many compounds, including fullerenes, aliphatic PFCs, nitrated explosives, phenols, and $\mathrm{PFB}$ derivatized phenols proved that the ionization mechanism of NI-DART was similar to NI-APPI. Therefore, NI-DART may be used to study in detail the ionization mechanism of LC/NI-APPI-MS. In this study, NIDART was used to detect and identify background ions from common LC solvents and APPI dopants. This became feasible because DART was coupled with a TOF mass spectrometer, which offered both high-resolution and the ability to transport and detect lower $\mathrm{m} / \mathrm{z}$ ions than previously used mass spectrometers.

With NI-DART, ambient air was able to produce many second generation background ions, including $\mathrm{O}_{2}^{-\cdot}(\mathrm{m} / \mathrm{z} 31.99,100 \%), \mathrm{NO}_{2}^{-\cdot}(\mathrm{m} / \mathrm{z} 45.99,6.3 \%), \mathrm{CO}_{3}^{-\cdot}(\mathrm{m} / \mathrm{z}$ $59.98,55.5 \%), \mathrm{HCO}_{3}^{-}(\mathrm{m} / \mathrm{z} 60.99,38.6 \%)$, and $\mathrm{HCO}_{4}^{-}(\mathrm{m} / \mathrm{z}$ $76.99,38.6 \%$ ). These ions were previously identified by us using toluene as dopant with NI-APPI, as the second generation of reactant ions in that method. This agreement between NI-DART and NI-APPI implies that NI-DART may be used to provide insight into the ionization mechanism of LC/NI-APPI-MS.

The second generation DART ions are consistent with the components of ambient air, arising from $\mathrm{O}_{2}$, of course, but also nitrogen, $\mathrm{NO}_{2}, \mathrm{CO}_{2}$, and water. In addition, there are very small $(<0.1 \%) \mathrm{O}^{-\cdot}, \mathrm{HO}^{-}$, and $\mathrm{HOO}^{-}$ion signals, possibly produced by a dissociative EC mechanism from water or oxygen. It is difficult to quantitate these low mass signals, due to the inherent mass discrimination of the quadrupole ion guide. Also, we infer $\mathrm{HOO}^{-}$from the excess intensity of the nominal $\mathrm{m} / \mathrm{z} 33$ peak, above the expected natural abundance of ${ }^{16} \mathrm{O}^{17} \mathrm{O}^{-.}$(observed $0.6 \%$ of $\mathrm{m} / \mathrm{z} 32$ at $100 \%$; calculated for ${ }^{16} \mathrm{O}^{17} \mathrm{O}^{-}: 0.038 \%$ ). Note that these small intensities could either be the result of little production, or of these ions' high reactivity: $\mathrm{HCO}_{3}^{-}(39 \%)$ is likely the product of $\mathrm{HO}^{-}$and $\mathrm{CO}_{2}, \mathrm{CO}_{3}^{-\cdot}$ at $56 \%$ corresponds to $\mathrm{O}^{-\cdot}$ plus $\mathrm{CO}_{2}$, and $\mathrm{HCO}_{4}^{-}(28 \%)$ is $\mathrm{HOO}^{-}$plus $\mathrm{CO}_{2}$. These highly 
basic ions $\left(\Delta \mathrm{H}_{\text {acid }}\right.$ corresponding to the conjugate base $\mathrm{HO}^{-}$is $390, \mathrm{O}^{-\cdot}$ is 383 , and $\mathrm{HOO}^{-}$is $376.5 \mathrm{kcal} / \mathrm{mol}$ ) appear to cluster with $\mathrm{CO}_{2}$ when no stronger acids are present, to form these "carbonated" ions. If acidic analytes are present, however, the basic ions yield deprotonated analyte species as well as their carbonated ions. The total abundance of basic ions plus their carbonated forms is comparable to that of the less basic $\left(\Delta \mathrm{H}_{\text {acid }}=353\right) \mathrm{O}_{2}^{-\cdot}$ base peak.

The third generation reactant ions, from common LC solvents and APPI dopants, are listed in Table 1. We cannot unambiguously assign the origin of any of these solvent ions to specific second generation ions, but can infer certain possible reaction pathways from relative abundances. $\mathrm{HO}^{-}$is certainly basic enough to yield the $[\mathrm{M}-\mathrm{H}]^{-}$ions observed in these spectra. Additional water does not alter the relative second generation ion abundances due to its presence in ambient air.

Acetonitrile yields an $[\mathrm{M}-\mathrm{H}]^{-}$ion, which can be produced exothermically from any of the three basic ions above. All three of the carbonated ions are depleted in abundance relative to the ambient air spectrum, consistent with all of the three basic ions being strong enough to deprotonate acetonitrile. There is also an $\left[\mathrm{M}-\mathrm{CH}_{3}+\mathrm{O}\right]^{-}$ion, i.e., $\mathrm{NCO}^{-}$, and its dimer ion observed. It is known that nucleophilic displacements can occur on acetonitrile [35], and further oxidation of cyanide by oxygen can explain this product.

The halogenated solvents chloroform and methylene chloride yield chloride as almost their sole ion (not listed in Table 1). This could be from dissociative EC. The consumption of thermal electrons by halogenated solvents would explain the greatly suppressed abundance of $\mathrm{O}_{2}^{-}$. In addition, a $\mathrm{Cl}^{-}$attachment product from chloroform was also observed with $6 \%$ relative intensity.

The alcoholic solvents methanol and 2-propanol show appreciable $[\mathrm{M}-\mathrm{H}]^{-}$ions, via exothermic proton transfer to the "missing" $\mathrm{HO}^{-}$and $\mathrm{O}^{-}$ions. The carbonated $\mathrm{HOO}^{-}$is not depleted, consistent with its weaker basicity. There are also $\mathrm{ROCO}_{2}^{-}$ions present, explicable by a proton loss $/ \mathrm{CO}_{2}$ addition process from $\mathrm{HCO}_{3}^{-}$or $\mathrm{HCO}_{4}^{-}$. In addition, an anion clustering product from 2-propanol with $\mathrm{O}_{2}^{-}$was also observed.

The alkanes (hexanes, heptane, and cyclohexane) show no $[\mathrm{M}-\mathrm{H}]^{-}$ions and are not expected to being far too weakly acidic to be deprotonated even by $\mathrm{HO}^{-}$. The $[\mathrm{M}-3 \mathrm{H}+\mathrm{O}]^{-}$ions observed for them are consistent with a mixture of $\mathrm{H}$ abstraction and $\mathrm{O}$ addition from $\mathrm{O}_{2}^{-\cdot}$ to form enolate-type anions [36]. Consistent with this, the three carbonated ions are not depleted, and even in part enhanced relative to $\mathrm{O}_{2}^{-}$. Acetone shows an $[\mathrm{M}-\mathrm{H}]^{-}$ion, exothermic via proton transfer to all the three basic ions; their carbonated ions are likewise depleted.

The aromatic solvents toluene and anisole react with $\mathrm{O}_{2}^{-\cdot}$ to generate phenolate anions, i.e., $\left[\mathrm{M}-\mathrm{H}+\mathrm{O}^{-}\right.$, $\left[\mathrm{M}-\mathrm{CH}_{3}+\mathrm{O}^{-}\right.$, and $\left[\mathrm{M}-\mathrm{OCH}_{3}+\mathrm{O}\right]^{-}$, by losing an aromatic hydrogen or other groups, e.g., $\mathrm{CH}_{3}$ and
$\mathrm{OCH}_{3}$. Notably, $\mathrm{O}_{2}^{-\cdot}$ is no longer the base peak in the anisole case, replaced by the $\left[\mathrm{M}-\mathrm{OCH}_{3}+\mathrm{O}^{-}\right.$.

The cyclic ethers THF and 1,4-dioxane are distinct in that these have greatly reduced $\mathrm{O}_{2}^{-}$signals, replaced by $\left[\mathrm{M}-\mathrm{H}+\mathrm{O}^{-}\right.$and $\left[\mathrm{M}-\mathrm{H}+\mathrm{O}_{2}\right]^{-}$ions as the base peaks. We believe that the $\mathrm{M}-\mathrm{H}$ component of these is not simple deprotonation, due to the very weak acidity of these ethers. Rather, $\beta$-elimination by the various bases present has occurred, to form a ring-opened alkene/ alkoxide, followed by further oxidation. For dioxane, there are additional ions at $\left[\mathrm{M}-28-\mathrm{H}+\mathrm{O}^{-},[\mathrm{M}-28-\right.$ $3 \mathrm{H}+\mathrm{O}^{-}$, and $\left[\mathrm{M}-28-3 \mathrm{H}+\mathrm{O}_{2}\right]^{-}$, which imply a second elimination involving loss of $\mathrm{C}_{2} \mathrm{H}_{4}$, leaving a glyoxal-based structure.

\section{Guidelines for LC/NI-APPI-MS: LC Solvents and APPI Dopant Selection}

In LC/NI-APPI-MS, it will be advantageous to use LC solvents that are able to promote ionization. On the other hand, it will be a disadvantage to use LC solvents that will hinder the ionization. To evaluate the effect of LC solvents and APPI dopants on the ionization, seven analytes, including 3-fluoroaniline, 4-cyanoaniline, 2-methylbenzoic acid, 3-nitroaniline, 3-trifluoromethylaniline, 2,4,6-trimethylbenzoic acid, and decanoic acid, were selected. They were dissolved at $2 \mu \mathrm{g} / \mathrm{mL}$ in the organic solvents listed in Table 1 and analyzed by NI-DART. These analytes were previously analyzed by NI-APPI, and their ionization was attributed to a proton transfer mechanism [26].

The gas-phase acidity, i.e., $\Delta \mathrm{H}_{\mathrm{acid}}$, of 3-fluoroaniline, 4-cyanoaniline, 2-methylbenzoic acid, 3-nitroaniline, 3-trifluoromethyl aniline, 2,4,6-trimethylbenzoic acid, and decanoic acid are 361.2, 348.8, 339.2, 352.3, 356.9, 339.0 , and $338.8 \mathrm{kcal} / \mathrm{mol}$, respectively. Since the gasphase acidity of $\mathrm{HO}_{2}$ is $353.0 \mathrm{kcal} / \mathrm{mol}$, strong $[\mathrm{M}-\mathrm{H}]^{-}$ ions of 4-cyanoaniline, 2-methylbenzoic acid, 3-nitroaniline, 2,4,6-trimethylbenzoic acid, and decanoic acid should be theoretically expected upon reaction with $\mathrm{O}_{2}^{-}$. This was consistent with NI-DART experiments when acetonitrile, methanol, 2-propanol, hexanes, heptane, cyclohexane, acetone, toluene, and anisole were used as solvent. On the other hands, $[\mathrm{M}-\mathrm{H}]^{-}$ions of 3-fluoroaniline and 3-trifluoromethlyaniline should not be thermochemically expected upon reaction with $\mathrm{O}_{2}^{-}$. Experimentally, this only held true when anisole was used as solvent. Weak $[\mathrm{M}-\mathrm{H}]^{-}$ions of 3trifluoromethlyaniline, and sometimes 3-fluoroaniline, were also observed when acetonitrile, methanol, 2propanol, hexanes, heptane, cyclohexane, acetone, and toluene were used as solvent, possibly due to the third generation of reactant ions from the solvents that were more basic than $\mathrm{O}_{2}^{-}$. Among them, acetone produced the strongest $[\mathrm{M}-\mathrm{H}]^{-}$ions of all seven analytes, probably due to the basic $\mathrm{CH}_{3} \mathrm{COCH}_{2}^{-}$ion in the background with relatively high intensity. A represen- 


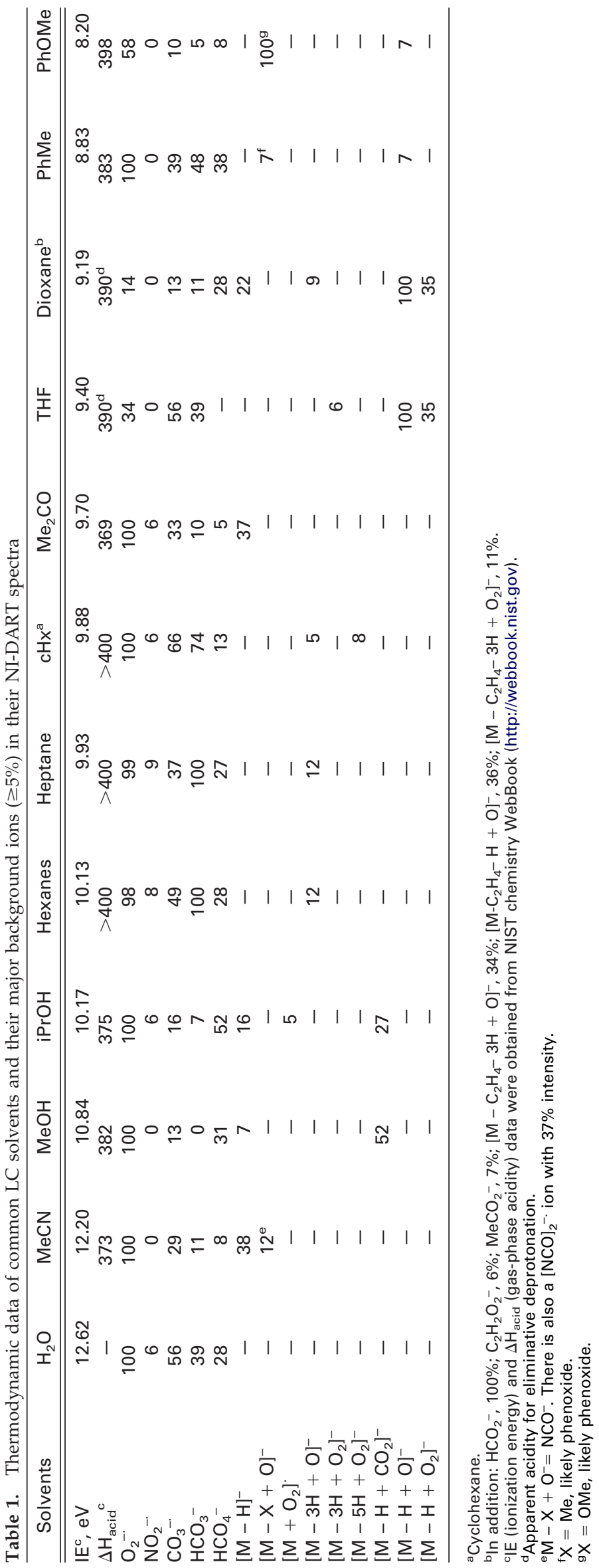



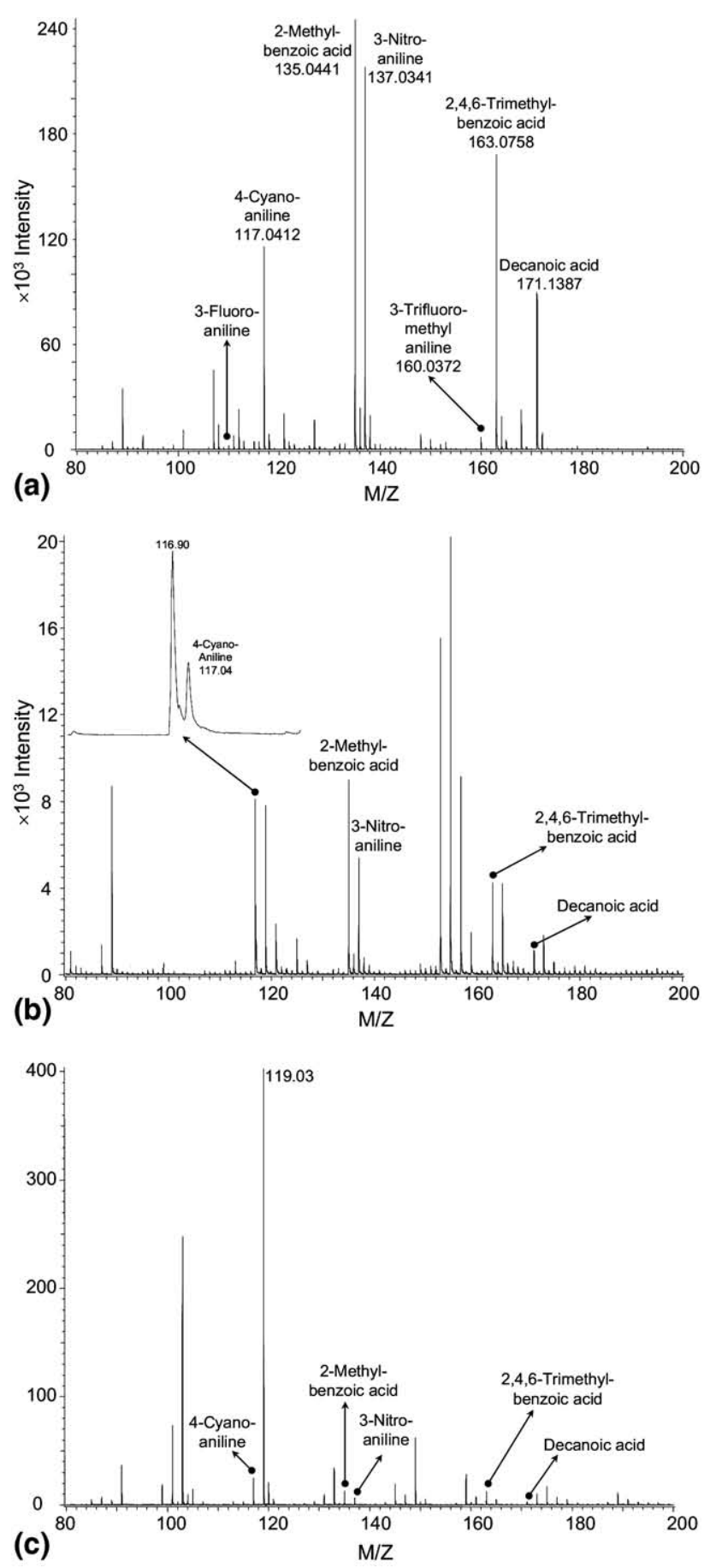

Figure 4. NI-DART spectra of $\sim 4$ ng 3-fluoroaniline, 4-cyanoanailine, 2-methylbenzoic acid, 3-nitroaniline, 3trifluoromethly aniline, 2,4,6-trimethylbenzoic acid, and decanoic acid at a concentration of $2 \mu \mathrm{g} / \mathrm{mL}$. Solvents: (a) acetone; (b) chloroform; (c) 1,4-dioxane. It is noted that in (b), the 4-cyanoaniline peak $(\mathrm{m} / \mathrm{z} 117.04)$ was still well separated from a much bigger adjacent background peak $\left(\mathrm{m} / z\right.$ 116.90, i.e., $\left.\mathrm{CCl}_{3}^{-}\right)$.

tative spectrum of the seven analytes by NI-DART using acetone as solvent is shown in Figure 4a.

When chloroform, methylene chloride, THF, and 1,4-dioxane were used as solvent, the ionization of the analytes was greatly suppressed. It is notable that these four are the only solvents tested in the DART experiments where the $\mathrm{O}_{2}^{-}$. signal was appreciably attenuated, and other ions became the base peaks. There were many background ions in the $\mathrm{m} / \mathrm{z} 80$ to 200 range with high intensity as well. Representative spectra of the seven analytes by NI-DART using chloroform and 1,4-dioxane as solvents are shown in Figure $4 \mathrm{~b}$ and c.

Due to their positive EAs, halogenated solvents are not good solvents for analytes that require ionization through EC, dissociative EC, or proton transfer mechanism. However, they are good solvents for analytes that require ionization through halogen anion attachment, e.g., RDX and HMX.

The primary criterion to select an APPI dopant is that the ionization energy should be lower than $10 \mathrm{eV}$, which is the photon energy from a $\mathrm{Kr}$ discharge lamp. As shown in Table 1, cyclohexane, acetone, THF, 1,4dioxane, toluene, and anisole all meet this requirement. In fact, acetone, toluene, and anisole are the most widely used dopants for PI-APPI [8, 9, 37], and we have exclusively used toluene for NI-APPI $[25,26]$. While cyclohexane, THF, and 1,4-dioxane have the potential to be used as dopants for NI-APPI, the highly abundant reactant ions from THF and 1,4-dioxane will pose a serious problem.

\section{Conclusions}

NI-DART and NI-APPI are totally different techniques and have totally different applications. However, in our experiments using over 42 compounds, including fullerenes, PFCs, organic explosives, phenols, PFB derivatized phenols, anilines, and carboxylic acids, NIDART generated ionization products similar to NIAPPI, leading to the conclusion that the same ionization mechanisms, including EC, dissociative EC, proton transfer, and anion attachment, were responsible for the ionization of the analytes. These four ionization mechanisms make both NI-DART and NI-APPI capable of ionizing a wider range of compounds than NI-APCI or NI-ESI. In consideration that both NI-DART and NIAPPI were operated under atmospheric pressure and both were initiated by thermal electrons, the conclusion became surprisingly understandable even though thermal electrons were generated through completely different pathways.

The significant difference between NI-DART and NI-APPI still remained: the operation of NI-DART was much easier. This provided us with opportunities to use NI-DART to study in detail the ionization mechanism of LC/NI-APPI-MS, which were well recognized to be complicated as many reactants, including nebulizing gas, auxiliary gas, surrounding air, dopant, solvent, buffer additives, and impurities, were involved. One such application was demonstrated in the detection and identification of background ions generated from 14 common LC solvents and APPI dopants, including water, acetonitrile, chloroform, methylene chloride, methanol, 2-propanol, hexanes, heptane, cyclohexane, acetone, tetra- 
hydrofuran (THF), 1,4-dioxane, toluene, and anisole. Possible reaction pathways leading to the formation of these background ions were further inferred.

\section{Acknowledgments}

LS thanks Dr. David C. Baker for providing some of the compounds used in this study, and Dr. Kelsey D. Cook for discussions in the ionization mechanism. The authors also thank Dr. Craig E. Barnes and the Department of Chemistry for their support. The authors greatly appreciate SARIF Equipment and Infrastructural Fund from the University of Tennessee.

\section{References}

1. Cody, R. B.; Laramee, J. A.; Durst, H. D. Versatile New Ion Source for the Analysis of Materials in Open Air Under Ambient Conditions. Anal. Chem. 2005, 77(8), 2297-2302.

2. Takats, Z.; Wiseman, J. M.; Cooks, R. G. Ambient Mass Spectrometry Using Desorption Electrospray Ionization (DESI): Instrumentation, Mechanisms, and Applications in Forensics, Chemistry, and Biology. J. Mass Spectrom. 2005, 40(10), 1261-1275.

3. Song, Y. S.; Cooks, R. G. Atmospheric Pressure Ion/Molecule Reactions for the Selective Detection of Nitroaromatic Explosives Using Acetonitrile and Air as Reagents. Rapid Commun. Mass Spectrom. 2006, 20(20), 3130-3138.

4. Haapala, M.; Pol, J.; Saarela, V.; Arvola, V.; Kotiaho, T.; Ketola, R. A.; Franssila, S.; Kauppila, T. J.; Kostiainen, R. Desorption Atmospheric Pressure Photoionization. Anal. Chem. 2007, 79(20), 7867-7872.

5. Fenn, J. B.; Mann, M.; Meng, C. K.; Wong, S. F.; Whitehouse, C. M. Electrospray Ionization for Mass-Spectrometry of Large Biomolecules. Science 1989, 246(4926), 64-71.

6. Whitehouse, C. M.; Dreyer, R. N.; Yamashita, M.; Fenn, J. B. Electrospray Interface for Liquid Chromatographs and Mass Spectrometers. Anal. Chem. 1985, 57(3), 675-679.

7. Horning, E. C.; Carroll, D. I.; Dzidic, I.; Horning, M. G.; Stillwell, R. N. Atmospheric-Pressure Ionization (API) Mass-Spectrometry-ContinuousFlow Liquid Chromatograph Mass Spectrometer-Computer (LC-MSCom) Analytical System Based on API Mass-Spectrometry. Abstracts of Papers of the American Chemical Society. 1974, 55-55.

8. Hanold, K. A.; Fischer, S. M.; Cormia, P. H.; Miller, C. E.; Syage, J. A. Atmospheric Pressure Photoionization. 1. General Properties for LC/ MS. Anal. Chem. 2004, 76(10), 2842-2851.

9. Robb, D. B.; Covey, T. R.; Bruins, A. P. Atmospheric Pressure Photoionization: An Ionization Method for Liquid Chromatography-Mass Spectrometry. Anal. Chem. 2000, 72(15), 3653-3659.

10. Haefliger, O. P.; Jeckelmann, N. Direct Mass Spectrometric Analysis of Flavors and Fragrances in Real Applications Using DART. Rapid Commun. Mass Spectrom. 2007, 21(8), 1361-1366.

11. Pierce, C. Y.; Barr, J. R.; Cody, R. B.; Massung, R. F.; Woolfitt, A. R.; Moura, H.; Thompson, H. A.; Fernandez, F. M. Ambient Generation of Fatty Acid Methyl Ester Ions from Bacterial Whole Cells by Direct Analysis in Real Time (DART) Mass Spectrometry. Chem. Commun. 2007, (8), 807-809.

12. Morlock, G.; Ueda, Y. New Coupling of Planar Chromatography with Direct Analysis in Real Time Mass Spectrometry. J. Chromatogr. A 2007, 1143(1/2), 243-251.

13. Petucci, C.; Diffendal, J.; Kaufman, D.; Mekonnen, B.; Terefenko, G.; Musselman, B. Direct Analysis in Real Time for Reaction Monitoring in Drug Discovery. Anal. Chem. 2007, 79(13), 5064-5070.

14. Kpegba, K.; Spadaro, T.; Cody, R. B.; Nesnas, N.; Olson, J. A. Analysis of Self-Assembled Monolayers on Gold Surfaces Using Direct Analysis in Real Time Mass Spectrometry. Anal. Chem. 2007, 79(14), 5479-5483.

15. Bos, S. J.; van Leeuwen, S. M.; Karst, U. From Fundamentals to Applications: Recent Developments in Atmospheric Pressure Photoionization Mass Spectrometry. Anal. Bioanal. Chem. 2006, 384(1), 85-99.

16. Raffaelli, A.; Saba, A. Atmospheric Pressure Photoionization Mass Spectrometry. Mass Spectrom. Rev. 2003, 22(5), 318-331.
17. Cai, S. S.; Syage, J. A. Atmospheric Pressure Photoionization Mass Spectrometry for Analysis of Fatty Acid and Acylglycerol Lipids. J. Chromatogr. A 2006, 1110(1/2), 15-26.

18. Cai, S. S.; Syage, J. A. Comparison of Atmospheric Pressure Photoionization, Atmospheric Pressure Chemical Ionization, and Electrospray Ionization Mass Spectrometry for Analysis of Lipids. Anal. Chem. 2006, 78(4), 1191-1199.

19. Ding, Y. S.; Ashley, D. L.; Watson, C. H. Determination of 10 Carcinogenic Polycyclic Aromatic Hydrocarbons in Mainstream Cigarette Smoke. J. Agr. Food. Chem. 2007, 55(15), 5966-5973.

20. Talyzin, A. V.; Tsybin, Y. O.; Purcell, J. M.; Schaub, T. M.; Shulga, Y. M.; Noreus, D.; Sato, T.; Dzwilewski, A.; Sundqvist, B.; Marshall, A. G. Reaction of Hydrogen Gas with C-60 at Elevated Pressure and Temperature: Hydrogenation and Cage Fragmentation. J. Phys. Chem. A 2006, 110(27), 8528-8534

21. Riu, A.; Zalko, D.; Debrauwer, L. Study of Polybrominated Diphenyl Ethers Using Both Positive and Negative Atmospheric Pressure Photoionization and Tandem Mass Spectrometry. Rapid Commun. Mass Spectrom. 2006, 20(14), 2133-2142.

22. Itoh, N.; Aoyagi, Y.; Yarita, T. Optimization of the Dopant for the Trace Determination of Polycyclic Aromatic Hydrocarbons by Liquid Chromatography/Dopant-Assisted Atmospheric-Pressure Photoionization/ Mass Spectrometry. J. Chromatogr. A 2006, 1131(1/2), 285-288.

23. Debrauwer, L.; Riu, A.; Jouahri, M.; Rathahao, E.; Jouanin, I.; Antignac, J. P.; Cariou, R.; Le Bizec, B.; Zalko, D. Probing New Approaches Using Atmospheric Pressure Photo Ionization for the Analysis of Brominated Flame Retardants and Their Related Degradation Products by Liquid Chromatography-Mass Spectrometry. J. Chromatogr. A 2005, 1082(1), 98-109

24. Moriwaki, H.; Ishitake, M.; Yoshikawa, S.; Miyakoda, H.; Alary, J. F. Determination of Polycyclic Aromatic Hydrocarbons in Sediment by Liquid Chromatography-Atmospheric Pressure Photoionization-Mass Spectrometry. Anal. Sci. 2004, 20(2), 375-377.

25. Song, L. G.; Wellman, A. D.; Yao, H. F.; Adcock, J. Electron Capture Atmospheric Pressure Photoionization Mass Spectrometry: Analysis of Fullerenes, Perfluorinated Compounds, and Pentafluorobenzyl Derivatives. Rapid Commun. Mass Spectrom. 2007, 21(8), 1343-1351.

26. Song, L. G.; Wellman, A. D.; Yao, H. F.; Bartmess, J. E. Negative Ion-Atmospheric pressure photoionization: Electron Capture, Dissociative Electron Capture, Proton Transfer, and Anion Attachment. J. Am. Soc. Mass Spectrom. 2007, 18(10), 1789-1798.

27. Kauppila, T. J.; Kotiaho, T.; Kostiainen, R.; Bruins, A. P. Negative Ion-Atmospheric Pressure photoionization-Mass Spectrometry. J. Am. Soc. Mass Spectrom. 2004, 15(2), 203-211.

28. Kauppila, T. J.; Kuuranne, T.; Meurer, E. C.; Eberlin, M. N.; Kotiaho, T.; Kostiainen, R. Atmospheric Pressure Photoionization Mass Spectrometry. Ionization Mechanism and the Effect of Solvent on the Ionization of Naphthalenes. Anal. Chem. 2002, 74(21), 5470-5479.

29. Gakh, A. A.; Tuinman, A. A.; Adcock, J. L.; Sachleben, R. A.; Compton, R. N. Selective Synthesis and Structure Determination of C60f48. J. Am. Chem. Soc. 1994, 116(2), 819-820.

30. Hettich, R. L.; Compton, R. N.; Tuinman, A.; Derecskeikovacs, A.; Marynick, D. S.; Dunlap, B. I. Attachment of 2 Electrons to C60f48Coulomb Barriers in Doubly-Charged Anions. Phys. Rev. Lett. 1994, 73(21), 2821-2824.

31. Wang, X. B.; Woo, H. K.; Huang, X.; Kappes, M. M.; Wang, L. S. Direct Experimental Probe of the On-Site Coulomb Repulsion in the Doubly Charged Fullerene Anion C-70(2-). Phys. Rev. Lett. 2006, 96(14).

32. Wang, X. B.; Woo, H. K.; Wang, L. S. Vibrational Cooling in a Cold Ion Trap: Vibrationally Resolved Photoelectron Spectroscopy of Cold C-60(-) Anions. J. Chem. Phys. 2005, 123(5).

33. Tubaro, M.; Marotta, E.; Seraglia, R.; Traldi, P. Atmospheric Pressure Photoionization Mechanisms. 2. The Case of Benzene and Toluene. Rapid Commun. Mass Spectrom. 2003, 17(21), 2423-2429.

34. Marotta, E.; Seraglia, R.; Fabris, F.; Traldi, P. Atmospheric Pressure Photoionization Mechanisms. 1. The Case of Acetonitrile. Int. J. Mass Spectrom. 2003, 228(2/3), 841-849.

35. Caldwell, G.; Rozeboom, M. D.; Kiplinger, J. P.; Bartmess, J. E. Anion Alcohol Hydrogen-Bond Strengths in the Gas-Phase. J. Am. Chem. Soc. 1984, 106(17), 4660-4667.

36. Dahlke, G. D.; Kass, S. R. The Ortho-Dehydrophenoxy Anion-an Unusual Ion Formed from a Surprising Reaction. Int. J. Mass Spectrom. 1992, 117(1/3), 633-645.

37. Kauppila, T. J.; Kostiainen, R.; Bruins, A. P. Anisole, a New Dopant for Atmospheric Pressure Photoionization Mass Spectrometry of Low Proton Affinity, Low Ionization Energy Compounds. Rapid Commun. Mass Spectrom. 2004, 18(7), 808-815. 